\title{
LA REFORMA CONSTITUCIONAL DE 2012 Y 2014 EN MATERIA DE SUSTITUCIÓN DEL PRESIDENTE DE LA REPÚBLICA ES INCONSISTENTE
}

\author{
Constitutional reform on replacing the president of the republic is inconsistent
}

Andrés GARRIDO DEL TORAL

\begin{abstract}
Sumario
I. Introducción. II. Marco teórico y árbol conceptual. III. El sistema de sustitución del Poder Ejecutivo en México. IV. Epílogo con nuevas reformas constitucionales al Ejecutivo Federal publicadas el 10 de febrero de 2014. V. Conclusiones. VI. Fuentes.
\end{abstract}

Resumen. El Poder Constituyente Permanente de México aprobó en 2012 varias alteraciones al sistema de sustitución por faltas temporales y absolutas del Ejecutivo de la Unión, introduciendo preceptos nuevos que vienen a llenar vacios legales constitucionales que tuvimos desde 1917, como el caso de que el secretario de Gobernación se convierta en presidente provisional hasta por sesenta días en caso de faltas temporales o absolutas del presidente en turno; o que si el presidente electo no se presentara de manera definitiva a protestar el cargo se erija como encargado del Ejecutivo federal al presidente del Senado de la República y, finalmente, que si el presidente electo no pudiera rendir protesta ante el Congreso General lo pueda hacer ante las mesas directivas de cada una de las cámaras, juntas, o en su defecto ante el presidente de la Suprema Corte de Justicia de la Nación.

Todo eso está bien, pero en su afán reformador - al igual que en las reformas más recientes del 2 de febrero de 2014-, no dejaron claros varios puntos importantes que definitivamente no contestan a la letra varias interrogantes que dejan vulnerable a la ingeniería constitucional mexicana.

Palabras clave. Ejecutivo Federal, Presidente de la República, Congreso de la Unión, Congreso General de los Estados Unidos Mexicanos, Congreso de la Unión, Elecciones directas, Elecciones indirectas, mayoría calificada, mayoría relativa, mayoría absoluta, presidente en funciones, presidente electo, presidente interino, presidente sustituto, presidente provisional, votación secreta, rendición de protesta.

Abstract. In the year of 2012, Mexico's Permanent Constituent Power approved several modifications to the substitution system in case of temporary or absolute absence of the Union's Executive, this introduced new precepts that have filled legal voids we have had since 1917. For example, the Secretary of the Interior may become Acting President for a period of up to sixty days, in case of temporary or permanent absence of the President. Furthermore, if the Presidentelect should fail definitely to perform the Oath of Office, then the President of the Senate will take charge of the Executive. Finally, should the President elect be prevented perform the Oath

\footnotetext{
${ }^{1}$ Doctor, profesor, investigador de tiempo completo de la Facultad de Derecho de la Universidad Autónoma de Querétaro, y director del Instituto de Estudios Constitucionales del Estado de Querétaro.
} 
of Office before the General Congress, the ceremony may take place before the chairs of both chambers, or if not possible, before the President of the Supreme Court of Justice.

These are all fine, but in it is enthusiasm to reform (just like in the more recent modifications done on February the 2nd, 2014), the Permanent Constituent Power left a number of relevant points unclear. These points fail to literally answer several questions, which vulnerates the Mexican constitutional engineering as a whole.

Key words: Federal Executive, President of the Republic, Congress of the Union, General Congress of the United States of Mexico, Direct elections, Indirect elections, Supermajority or qualified majority, Relative majority or plurality, President in function, President-elect, Interim President, Substitute President, Provisional President, Secret Voting, Constitutional Oath.

\section{INTRODUCCIÓN}

A pesar de las reformas de 2012 y 2014, no hay claridad para responder a las siguientes hipótesis:

¿Rinden protesta el secretario de Gobernación y el presidente del Senado de la República una vez que son investidos de manera provisional como encargados del Ejecutivo Federal? ¿Ante quién sería, en caso de la afirmativa?

Tanto el secretario de Gobernación como el presidente del Senado de la República, una vez investidos como encargados provisionales del Poder Ejecutivo Federal ¿pueden ser ratificados — sin haber dejado el cargo - como presidente interino o sustituto, ya que no se han separado del puesto y no se les aplicaría el principio de la no reelección relativa dispuesto en el numeral 83 de la Carta de Querétaro?

Se regula que el presidente de la República pida licencia temporal o renuncie por causa grave que califique el Congreso, pero nunca se ha dispuesto solicitarle su renuncia o aún deponerlo por caso de desafuero, violaciones graves a la Constitución o enfermedad mental o incapacidad física calificada por un grupo de especialistas.

Tampoco se ha previsto qué pasaría si el electo no se presentara el $1^{\circ}$ de diciembre del año que toque, y como no corresponde que suba el presidente del Senado - porque no es falta definitiva-, el Congreso General tendría que nombrar un interino o que sea investido el secretario de Gobernación de la administración saliente, y que luego de unos días se le ocurra al presidente electo presentarse reclamando su derecho por haber sido elegido legal y legítimamente además de contar con la constancia de mayoría expedida por el Tribunal Electoral citado ¿cómo resolverían este embrollo en la Corte o en el Congreso?

Ninguna de estas preguntas se pueden contestar de manera fácil, y menos por los que no estén familiarizados con el apasionante mundo del Derecho Constitucional y las técnicas de interpretación, por lo que desarrollé el presente trabajo siguiendo el método formalista y el método deductivo, acudiendo a destacados doctrinarios, al texto de las constituciones mexicanas anteriores, a las exposiciones de motivos, a los dictámenes de comisiones legislativas y a los diarios de los debates, utilizando las técnicas generalmente aceptadas de interpretación jurídica y constitucional. 


\section{MARCO TEÓRICO Y ÁRBOL CONCEPTUAL}

Los conceptos más recurrentes en el presente trabajo son:

Ejecutivo Federal: El titular de la jefatura de estado y de gobierno en México.

Presidente de la República: Sinónimo del anterior, pero en este caso me refiero a la persona física que lo titulariza y no al órgano. Es un puesto unipersonal, electo de manera popular y directa en elecciones ordinarias o extraordinarias, a menos que sea designado por el Congreso General de los Estados Unidos Mexicanos en forma interina o sustituta, o sea por ministerio de ley como en el caso del secretario de Gobernación o el presidente del Senado de la República como referí líneas arriba.

Congreso de la Unión: Las cámaras de diputados y senadores trabajando en el mismo proyecto pero cada una en su recinto.

Congreso General: Las dos cámaras reunidas en el mismo recinto trabajando en el mismo proyecto.

Elecciones directas: Aquellas en que no hay intermediario entre el elector (pueblo) y el elegido.

Elecciones indirectas: Aquellas en que hay intermediarios de segundo a cuarto grado entre el elector primario (pueblo) y el elegido.

Mayoría absoluta: Es la que está integrada por más de la mitad de los votantes y es la que decide ordinariamente cuando existen dos proposiciones. Es impropio decir que la mayoría absoluta está integrada por la mitad más uno del total de votantes, pues cuando dicho total está formado por un número impar la mitad exacta es imposible. ${ }^{2}$

Mayoría relativa: Es la que decide entre más de dos proposiciones y de ellas obtiene el triunfo la que alcanza mayor número de votos, aunque ese número no exceda de la mitad del total de votantes.

Presidente en funciones: Aquel que está ejerciendo el cargo. Este concepto es mucho más adecuado que el usado corrientemente como "presidente constitucional", ya que todos - encargado por ministerio de ley, interino, sustituto y provisional — son designados conforme a la Constitución. ${ }^{3}$

Presidente virtual: Aquel que ha obtenido la mayoría relativa en las elecciones populares y al que el escrutinio del Instituto Nacional Electoral considera ganador.

Presidente electo: Aquel que ha recibido la constancia de mayoría por resolución del Tribunal Electoral del Poder Judicial de la Federación, a través de su Sala Superior, haya o no haya conflicto post electoral, pero que no ha tomado posesión del cargo.

\footnotetext{
2 TENA RAMÍREZ, Felipe, Derecho Constitucional Mexicano, 29a ed., Porrúa, México. 1995, p. 281.

3 SAYEG HELÚ, Jorge, Instituciones de Derecho Constitucional Mexicano, Porrúa, México, 1987, p. 338.
} 
Presidente interino: Aquel que es nombrado por el Congreso General cuando no hubo elecciones o, que habiéndolas, fueron declaradas inválidas. También se le llama así al que nombra el Congreso General cuando ocurre falta definitiva del presidente en funciones los primeros dos años del período. El presidente interino nunca termina el período sino que entrega a quien es electo en elecciones extraordinarias que tiene lugar en un plazo de siete a nueve meses a partir de que se convocó a las mismas.

Presidente sustituto: Aquel que es nombrado por el Congreso General por falta absoluta del presidente en funciones ocurrida dentro de los últimos cuatro años del período. El presidente sustituto sí termina el período sexenal.

Presidente provisional: Se le denomina así a quien ocupa el Ejecutivo Federal por faltas temporales o definitivas del presidente en funciones en un plazo no mayor a sesenta días y que el Congreso no esté reunido. En este caso es investido como tal el secretario de Gobernación para no dejar sin jefe de Estado y de Gobierno a México. Cuando se reúna el Congreso General se designará presidente interino o sustituto según sea el caso. Lo mismo ocurre con el presidente del Senado designado de manera provisional por ministerio de ley cuando el presidente electo no se presenta a rendir protesta. Cuando se reúna el Congreso General se designará presidente interino o sustituto según sea el caso, dependiendo del año del sexenio que corre.

Votación secreta o por cédula: Se verifica mediante la entrega que los legisladores hacen al presidente de su respectiva cámara en la que se inscribe el nombre de la persona por la que se ha pronunciado el emitente para que ocupe un puesto o cargo. Debido a que el presidente cameral tiene prohibido dar lectura a las boletas en el momento de recibirlas, se trata de un escrutinio secreto. ${ }^{4}$

Protesta constitucional: No es una solemnidad, es una formalidad que todo servidor público debe hacer comprometiéndose a respetar el marco constitucional y jurídico, so pena de que la sociedad se lo demande. Tratándose del presidente de la República, es rendición de protesta, porque nadie se la toma sino que él levanta su brazo derecho y la rinde sin que nadie lo exhorte a tal cosa. Otro tipo de nombramientos y elecciones sí son sujetos a toma de protesta, en la que el superior jerárquico o el miembro de más antigüedad en un órgano colegiado la toma a sus pares.

En el presente trabajo demostraré que el Poder Constituyente Permanente dio como preceptos suficientemente explicados los que son producto de actividad reformatoria pero sólo acrecentaron las dudas de los estudiosos y llegado el caso pudieran provocar interpretaciones no muy serias y hasta interesadas en caso de que llegara a faltar el Ejecutivo Federal.

¿Por qué no mejorar la técnica legislativa en lugar de obligar al ciudadano y al estudioso a buscar significados verdaderos en engorros expedientes legislativos que no están al alcance o comprensión de muchos mexicanos?

\footnotetext{
4 ARTEAGA NAVA, Elisur, Derecho Constitucional, 2 ${ }^{\mathrm{a}}$ ed., Oxford University Press, México, 2001, pp. 168-169. 
Una de las cosas que se le aplaudieron al Constituyente de 1916-1917 fue el que haya inventado para México un sistema de sustitución del titular del Ejecutivo Federal --por faltas absolutas y temporales del presidente en funciones--, en el que no se supiera de antemano quién lo sustituiría, porque de lo contrario se alentaban apetitos políticos muchas veces alimentados por la codicia y la traición, mismos que hundieron en la inestabilidad a nuestro país por casi toda la centuria decimonónica. Tal fue el caso de cuando tuvimos vicepresidente de la República como resultado de haber quedado en segundo lugar en las votaciones. ¡El peor enemigo del ganador era su segundo a bordo! ${ }^{6}$ Este sistema lo copiamos de Estados Unidos cuando ya la Constitución de Filadelfia había sido reformada en 1804 precisamente por haber sido considerado negativo. Con las constituciones centralistas de $1835-1836$ y 1843 fungió como vicepresidente el presidente del Consejo de Gobierno en faltas temporales y en las faltas mayores o definitivas el Senado designaba interino. En el Acta de Reformas y Adiciones de 1847 la Cámara de Diputados designaba al interino y, si no estaba reunida ésta, se encargaban de la presidencia el presidente de la Suprema Corte de Justicia y dos personas electas por el Consejo de Gobierno. Después tuvimos al presidente de la Suprema Corte de Justicia en funciones de vicepresidente de la República, que en todo caso era casi igual al sistema anterior, porque precisamente resultaba presidente del Poder Judicial quien había quedado en segundo lugar en las elecciones presidenciales. En el Porfiriato se enmienda la Constitución de 1857 en 1882 y el sustituto fue el presidente del Senado o el presidente de la Comisión Permanente en su caso. En 1896 la sustitución recaía en el secretario de Relaciones Exteriores o en el de Gobernación mientras el Congreso realizaba la elección, y en 1904 se dispone que los candidatos a presidente y vicepresidente de la República vayan en fórmula, es decir, sean electos de manera conjunta para evitar, en lo posible, rivalidades.

Pues bien, el sistema de la Constitución de 1917 fue casi perfecto, por considerarse que la sustitución del presidente en funciones nunca recaía en una persona predeterminada, ${ }^{7}$ considerando Carpizo que la vicepresidencia era una institución chocante para el movimiento social mexicano a raíz de las muertes de Madero y Pino Suárez, ${ }^{8}$ adicionando Tena Ramírez que los defectos y mala voluntad se atribuyeron por los revolucionarios a la institución de la vicepresidencia y al sistema de sustitución mismos en lugar de hacerlo a los acontecimientos del asesinato de los altos funcionarios, ${ }^{9}$ y no era cuestionado casi por nadie hasta que la elección del año 200o, en la persona de Vicente Fox, y luego la de 2006 en la de Felipe Calderón, nos llevó a preguntarnos ¿qué pasaría si el Congreso General no se reuniera para recibir la protesta del presidente electo? ¿Era una solemnidad o simple formalidad la rendición de la protesta? ¿Era presidente de la República desde las cero horas del $1^{\circ}$ de diciembre en que tomaba el mando de la fuerza pública o hasta las once de la mañana en que rendía protesta

\footnotetext{
5 Aunque Daniel Moreno lo llame complicado y poco afortunado, en Derecho Constitucional Mexicano, $6^{\mathrm{a}}$ ed., Editorial Pax México, México, 1981, p. 420.

${ }^{6}$ Dice Jorge Carpizo que este sistema está entre los peores que hemos tenido para sustituir al presidente en funciones, en El presidencialismo mexicano, $5^{\mathrm{a}}$ ed., Siglo Veintiuno Editores, México, 1985, p. 63.

7 "....nadie puede tener la seguridad inconmovible de sustituir al presidente hasta que cualquiera de los mencionados órganos (Congreso General o Comisión Permanente) formule la designación correspondiente", en BURGOA ORIHUELA, Ignacio, Derecho Constitucional Mexicano, $5^{\text {a }}$ ed., Porrúa, México, 1984, p. 763.

${ }^{8}$ CARPIZO, Jorge, Op. Cit., p. 64 .

9 TENA RAMÍREZ, Felipe, Op. Cit., p. 454.
} 
ante el Congreso General en el palacio de San Lázaro ${ }^{10}$ La Carta Magna no tenía respuesta a estas interrogantes. La ingeniería constitucional mexicana había sido hecha para un país de presidente fuerte, dotado inclusive de facultades metaconstitucionales y con el apoyo de un partido político que primero fue hegemónico y después mayoritario para finalmente perder la presidencia de la República en el año 2000. Pero en los años 2000 y 2006 en que ya no había un hombre fuerte ni un partido ultra dominante ¿quién decidiría en caso de una falta de quórum en el Congreso General para recibir la protesta presidencial? No había vías alternas claras.

Muchos opinamos en los medios de comunicación - y en eventos académicos-, que ya era dicha persona presidente de la República a partir de las cero horas del $1^{\circ}$ de diciembre respectivo, porque la rendición de protesta es una simple formalidad y no una solemnidad como lo aseguran de manera irresponsable los civilistas y los profesores de Teoría del Derecho al no encontrar otro ejemplo de acto solemne además del matrimonio y testamento. La solemnidad es el conjunto de requisitos legales para la existencia de un acto jurídico al que la ley le da el carácter de solemne. Todo acto jurídico requiere para existir de cuando menos dos elementos: voluntad y objeto. La formalidad es una mera exigencia legal de exteriorizar la voluntad de cierta manera, es un mero requisito de validez y tiene la finalidad de garantizar la seguridad jurídica a efecto de evitar errores o fraudes producto de las complicaciones de la vida jurídica moderna. ${ }^{11}$ Las formalidades son el conjunto de normas establecidas por el orden jurídico o por las partes que señalan cómo debe exteriorizarse la voluntad para la validez del acto jurídico. ${ }^{12}$

Para mí, la solemnidad está en la elección popular y en la calificación que hace de ésta el Tribunal Electoral del Poder Judicial de la Federación y en la publicación del bando solemne proclamatorio que realiza la Cámara de Diputados del Congreso de la Unión.

Siguiendo a Felipe Tena Ramírez ${ }^{13}$ también cuestiono el que en el sistema ideado en la Carta Magna de 1917 y en las reformas de 2012 y 2014 no se haya previsto qué hacer en el caso de que el Congreso General al tratar de elegir presidente interino o sustituto no alcance la mayoría exigida para hacerlo válidamente en favor de un candidato, y que la Constitución de 1824 sí previó que en ese caso entrara a sustituir el presidente de la Suprema Corte de Justicia de la Nación: ¿Acaso el secretario de Gobernación o el presidente del Senado de la República pueden ejercer por un plazo largo el cargo provisionalmente si esa figura de sustitución se hizo precisamente para no dejar acéfala la jefatura de estado?

Con estas reflexiones se hace la reforma a los numerales constitucionales 83,84 y 85 , en un intento de clarificar la interpretación de las normas supremas relativas al tema en comento y de llenar vacíos sensibles en nuestra ingeniería política constitucional. Fruto de la reforma, el texto quedó así:

\footnotetext{
${ }^{10}$ Para Carpizo la protesta no constituye el cargo, porque con o sin ella, el presidente está obligado a guardar y hacer guardar la Constitución, además sería poner la protesta por encima de las propias elecciones. La protesta es de carácter formal, aunque importante, porque es la manifestación pública de la subordinación del presidente al orden jurídico. El presidente lo es desde que comienza el $1^{\circ}$ de diciembre. Véase CARPIZO, Jorge, Op. Cit., p. 62.

11 SOBERÓN MAINERO, Miguel, Diccionario jurídico mexicano, Instituto de Investigaciones JurídicasUNAM-Porrúa, México, 2005, pp. 3559-3560.

${ }^{12}$ CÁRDENAS CAMACHO, Alejandro, Diccionario jurídico mexicano, Instituto de Investigaciones JurídicasUNAM-Porrúa, México, 2005, p. 1722.

13 TENA RAMÍREZ, Felipe, Op. Cit., p. 456.
} 
Artículo 83. El Presidente entrará a ejercer su encargo el 1o. de octubre y durará en él seis años. El ciudadano que haya desempeñado el cargo de Presidente de la República, electo popularmente, o con el carácter de interino o sustituto, o asuma provisionalmente la titularidad del Ejecutivo Federal, en ningún caso y por ningún motivo podrá volver a desempeñar ese puesto.

Se reforzó el principio de la no reelección absoluta del presidente de la República para cualquier persona que la haya ocupado bajo alguna de sus modalidades, incluyendo a quien la ocupe de manera provisional, tal y como sería el caso del secretario de Gobernación y el presidente del Senado de la República. Aquí el Poder Constituyente Permanente que efectuó la reforma constitucional del 2 de febrero de 2014 corrigió ortografía y estilo quitando la decimonónica palabra "substituto" para cambiarla por la moderna "sustituto", pero dejando el equívoco en repetidas ocasiones en el artículo 84. ¿Por qué no se fijan para hacer una reforma integral?

Con todo y prohibición del artículo 83 para que nadie pueda ser reelecto al cargo de presidente de la República, sea cual fuere la denominación, no me contesta la pregunta sobre si tanto el secretario de Gobernación como el presidente del Senado de la República, una vez investidos como encargados provisionales del Poder Ejecutivo Federal ¿pueden ser ratificados-sin haber dejado el cargo- como presidente interino o sustituto, ya que no se han separado del puesto y no se les aplicaría el principio de la no reelección relativa dispuesto en el numeral 83 de la Carta de Querétaro? El texto aprobado carece de claridad, y encuentro la respuesta en los debates y en la entrevista que le hice al diputado federal Jesús Rodríguez Hernández - vicepresidente de la Mesa Directiva durante la reforma y presidente de la Comisión de Prácticas Parlamentarias-, donde se aprecia que en el transcurso de los debates se hicieron esta interrogante y la respuesta que encontraron fue de que no se permitía que el presidente provisional, en ninguna de las hipótesis, fuera ratificado por el Congreso General como interino o sustituto.

Observe bien atento lector que esta conclusión es en base a mis investigaciones y no resultado de una lectura fácil y accesible para todos del texto enmendado. ¿Qué se les hacía repetitivo a los legisladores enfatizarlo? Hubiera ganado la claridad, además de que muchos preceptos de la Carta Magna son repetitivos en aras a despejar dudas, tal y como lo hacen los decimonónicos numerales 117, 118 y 120.

Artículo 84. En caso de falta absoluta del Presidente de la República, en tanto el Congreso nombra al presidente interino o substituto, lo que deberá ocurrir en un término no mayor a sesenta días, el Secretario de Gobernación asumirá provisionalmente la titularidad del Poder Ejecutivo. En este caso no será aplicable lo establecido en las fracciones II, III y VI del artículo 82 de esta Constitución.

Aquí parece que no hay ninguna inconsistencia en el texto renovado, simplemente se mejora el sistema para no esperar que la Comisión Permanente se reúna y nombre presidente provisional, sino que lo haga de manera inmediata y hasta por sesenta días el Secretario de Gobernación, a quien no se le pedirían los requisitos de residencia en un año inmediato al día de la elección, el de no ser secretario de Estado ni el de la edad de 35 años. Donde sí noto inconsistencia es en el dictamen de abril 22 de 2012 en la Cámara de Diputados, cuya comisión de dictamen reconoce coincidir con la Cámara de Senadores en que había que eliminar 
al presidente provisional. ¡Vaya argumento, porque si bien ya no le llaman así de manera expresa, sí están reconociendo que el Secretario de Gobernación cubre faltas temporales y absolutas de hasta sesenta días al ausentarse del cargo el presidente en funciones! A esa figura se le llama presidente provisional, aunque nuestros flamantes legisladores lo traten de encubrir con sofismas. Lo mismo ocurre con el presidente del Senado en faltas definitivas cuando el presidente electo no se presenta a protestar el cargo.

Quien ocupe provisionalmente la Presidencia no podrá remover o designar a los Secretarios de Estado, sin autorización previa de la Cámara de Senadores. Asimismo, entregará al Congreso de la Unión un informe de labores en un plazo no mayor a diez días, contados a partir del momento en que termine su encargo.

En este segundo párrafo del numeral 84, noto el refuerzo de matices parlamentarios a nuestro sistema presidencialista, porque quien llegue a la presidencia de la República de manera "provisional" (ojo), no podrá remover o designar a los secretarios de Estado, ${ }^{14}$ sin autorización previa de la Cámara de Senadores. Asimismo, entregará al Congreso de la Unión un informe de labores en un plazo no mayor a diez días, contados a partir del momento en que termine su encargo. Todo esto son limitaciones al presidente provisional y por ende lo considero como un fuerte matiz parlamentario.

Cuando la falta absoluta del Presidente ocurriese en los dos primeros años del período respectivo, si el Congreso de la Unión se encontrase en sesiones y concurriendo, cuando menos, las dos terceras partes del número total de los miembros de cada Cámara, se constituirá inmediatamente en Colegio Electoral y nombrará en escrutinio secreto ${ }^{15}$ y por mayoría absoluta de votos, un presidente interino, en los términos que disponga la Ley del Congreso. El mismo Congreso expedirá, dentro de los diez días siguientes a dicho nombramiento, la convocatoria para la elección del Presidente que deba concluir el período respectivo, debiendo mediar entre la fecha de la convocatoria y la que se señale para la realización de la jornada electoral, un plazo no menor de siete meses ni mayor de nueve. El así electo iniciará su encargo y rendirá protesta ante el Congreso siete días después de concluido el proceso electoral.

Si el Congreso no estuviere en sesiones, la Comisión Permanente lo convocará inmediatamente a sesiones extraordinarias para que se constituya en Colegio Electoral, nombre un presidente interino y expida la convocatoria a elecciones presidenciales en los términos del párrafo anterior.

Aquí la reforma lo que hizo fue adaptar los tiempos a la actualidad en el sentido de que no había caso que las elecciones extraordinarias tuvieran lugar entre 14 y 18 meses después de que se elegía al presidente interino por falta absoluta del presidente en funciones durante los dos primeros años del período. Con la reforma se acorta ese plazo para quedar entre siete y nueve meses. También es novedad la última parte de este párrafo cuando dispone que el pre-

\footnotetext{
14 Con la reforma de 2012 se incluía en esta prohibición de nombramiento remoción al procurador general de la República, pero con la reforma de 2014 se dio por hecho que nunca podrá remover libremente al fiscal general de la República que entrará en vigencia y funciones en el 2018.

${ }^{15}$ Carpizo encuentra aquí, en la secrecía del voto, una garantía y seguridad de libertad para los legisladores a la hora de ejercer su voto. Véase CARPIZO, Jorge, Op. Cit., p. 66.
} 
sidente así electo iniciará su encargo y rendirá protesta ante el Congreso siete días después de concluido dicho proceso electoral extraordinario.

Me permitiré hacer algunas precisiones al párrafo transcrito: se dice sin duda alguna que ese presidente electo de manera extraordinaria es nada más para terminar el período que quedó inconcluso por la falta absoluta del presidente electo de manera popular y directa en la elección ordinaria. Lástima que el texto constitucional no sea tan detallista y técnico como la Ley Orgánica del Congreso que sí diferencia entre Congreso General y Congreso de la Unión, ya que quien elige al interino y al sustituto no es el Congreso de la Unión sino el Congreso General, mismo que emite la convocatoria para la elección extraordinaria y recibe la protesta del presidente electo en comicios ordinarios (los de cada seis años) u extraordinarios. El último párrafo sólo regula la hipótesis sobre si está el Congreso o no reunido, para que en caso negativo la Comisión Permanente lo convoque a sesiones extraordinarias y se erija en Colegio Electoral para elegir al presidente interino. El Poder Reformador no tuvo la valentía de suprimir de una vez para siempre ese vocablo de "Colegio Electoral" que se usaba mucho en la época del presidencialismo unipartidista en que el Poder Legislativo Federal lo mismo autocalificaba sus propias elecciones que convocaba a elecciones extraordinarias presidenciales o de senadores o diputados federales que se ausentaban de manera definitiva. ${ }^{16}$ Desde que existen el ahora Instituto Nacional Electoral (desde 1990 a 2014 Instituto Federal Electoral) y el Tribunal Electoral del Poder Judicial de la Federación, la auto calificación terminó para pasar a la heterocalificación, pero en las otras hipótesis sigue funcionando la figura cuyo nombre me parece desafortunado y pasado de moda.

Cuando la falta absoluta del Presidente ocurriese en los cuatro últimos años del período respectivo, si el Congreso de la Unión se encontrase en sesiones, designará al presidente sustituto que deberá concluir el período, siguiendo, en lo conducente, el mismo procedimiento que en el caso del presidente interino. ${ }^{17}$

Si el Congreso no estuviere reunido, la Comisión Permanente lo convocará inmediatamente a sesiones extraordinarias para que se constituya en Colegio Electoral y nombre un presidente substituto siguiendo, en lo conducente, el mismo procedimiento que en el caso del presidente interino. En esta parte sólo me queda criticar la palabra "substituto" que provocó más e algún acalorado debate entre las dos cámaras, pero se fueron por la vía fácil de dejar el texto y ortografía original con un lenguaje decimonónico y pasado de moda. También critico que este numeral disponga la elección del sustituto por el Congreso de la Unión cuando en realidad lo hace el Congreso General. Por lo demás se deduce que si no está en sesiones el Congreso, la Comisión Permanente convoca a sesiones extraordinarias, y mientras se encarga del despacho del Poder Ejecutivo Federal el secretario de Gobernación ante esa falta absoluta. ${ }^{18}$

\footnotetext{
16 “se trata del Congreso de la Unión, que actúa en cámara única, con un quórum especial...”, en ARTEAGA NAVA, Elisur, Op. Cit., p. 171. Aunque yo prefiero llamarlo Congreso General.

${ }^{17}$ La partición del período sexenal en los dos primeros años y últimos cuatro años para el caso de elegir presidente interino o sustituto, Carpizo la explica como una reminiscencia de cuando el período constitucional era de cuatro años antes de la reforma de 1933. Véase CARPIZO, Jorge, Op. Cit., p. 66.

${ }^{18}$ Carpizo critica que no se haya señalado plazo cierto a la Comisión Permanente para convocar a sesiones del Congreso y así darle velocidad al nombramiento respectivo. Véase CARPIZO, Jorge, Op. Cit., p. 66.
} 
Artículo 85. Si antes de iniciar un periodo constitucional la elección no estuviese hecha o declarada válida, cesará el Presidente cuyo periodo haya concluido y será presidente interino el que haya designado el Congreso, en los términos del artículo anterior.

En este primer párrafo del numeral 85 se prevé la hipótesis de que si la elección no se hubiere llevado a cabo o que, si la misma hubiere ocurrido y no hubiese sido declarada válida, entonces el Congreso General debe nombrar un presidente interino para convocar luego el mismo Congreso General a elecciones extraordinario tal y como lo explicamos líneas arriba cuando estudié el artículo 84. En este caso no entran ni el presidente del Senado de la República ni el secretario de Gobernación de la administración saliente, porque ambas hipótesis son perfectamente bien previsibles y hay tiempo de sobra para reunir al Congreso General y que éste nombre presidente interino.

Si al comenzar el periodo constitucional hubiese falta absoluta del Presidente de la República, asumirá provisionalmente el cargo el Presidente de la Cámara de Senadores, en tanto el Congreso designa al presidente interino, conforme al artículo anterior.

En este segundo párrafo del numeral 85 sí podemos hablar de una contingencia poco previsible, pues se trata de, si a las cero horas del día $1^{\circ}$ de diciembre del año que ocurran elecciones ordinarias, el presidente electo cuya elección fue calificada de válida no se presentare, pues entonces asumiría el cargo de manera temporal o provisional el presidente del Senado en tanto se reúne el Congreso General para elegir al presidente interino conforme al artículo 84. Mucho se discutió en las sesiones del poder reformador el por qué se encargaría del Poder Ejecutivo Federal el presidente del Senado y no el de la Cámara de Diputados que es a la vez presidente del Congreso General: esgrimían los diputados que los senadores representan a las partes integrantes de la Federación Mexicana pero no a la población como es el caso de los diputados, y que además éstos son 500 y los senadores sólo 128.

Cuando el Presidente solicite licencia para separarse del cargo hasta por sesenta días naturales, una vez autorizada por el Congreso, el Secretario de Gobernación asumirá provisionalmente la titularidad del Poder Ejecutivo.

Si la falta, de temporal se convierte en absoluta, se procederá como dispone el artículo anterior.

Al desaparecer la figura del presidente provisional, mediante designación de la Comisión Permanente, se consideró que para esas faltas temporales del presidente en funciones de hasta por sesenta días naturales, el secretario de Gobernación asuma de manera provisional el Poder Ejecutivo Federal. Si la falta pasa de temporal a definitiva se estará a lo dispuesto por el numeral 84, es decir, que el Congreso General nombre presidente interino o sustituto según sea el año del sexenio en que ocurra la falta definitiva. Por cierto que quien califica la licencia temporal o renuncia definitiva del presidente en funciones no es el Congreso de la Unión sino el Congreso General.

Quiero hacer énfasis de que la autorización para la renuncia del presidente de la República es competencia del Congreso General y no del Congreso de la Unión, aunque el numeral 86 disponga que: 
El cargo de Presidente de la República sólo es renunciable por causa grave, que calificará el Congreso de la Unión, ante el que se presentará la renuncia.

Ya expliqué la diferencia entre uno y otro órgano, y ya dejé claro que los asuntos más relevantes del país le tocan al Congreso General, porque están reunidas ambas cámaras en un mismo recinto trabajando un mismo proyecto. Si fuera el Congreso de la Unión el que tuviera que calificar la renuncia por causa grave del presidente en funciones ¿cómo se contarían los votos de los 628 miembros del Congreso General? ¿Cada cámara haría su conteo sobre la asistencia a cada una en lo individual y verificando su propio quórum o sólo lo haría parcialmente cada una de ellas para después sumar los votos y las asistencias de sus miembros? Parece poco práctico que fuera el Congreso de la Unión, ya que es más fácil determinar el quórum y el sentido de la votación en un solo órgano colegiado como es el Congreso General, donde las matemáticas serían más fáciles de aplicar e interpretar. Lo mismo digo acerca de la fracción XXVI del artículo 73 en materia de licencias temporales dl presidente en funciones. No hay que olvidarnos de que el Constituyente de 1916-1917 tuvo errores de técnica jurídica de manera repetida y que a lo mejor los vocablos de Congreso General y de Congreso de la Unión le parecieron sinónimos sin advertir las diferencias que sí marca la ley secundaria. Para reforzar esta idea del equívoco basta con leer el encabezado del artículo 73 constitucional en que el Constituyente no diferencia si se trata de facultades o competencia del Congreso General o de Congreso de la Unión, simplemente escribió “Congreso" y revolvió la competencia de ambos órganos en solo artículo, entuerto que a veces resuelve la ley orgánica mal llamada "del Congreso General de los Estados Unidos Mexicanos", en lugar de denominarse "Ley Orgánica del Poder Legislativo Federal".

El numeral 73 de la Carta Magna, en sus fracciones XXVI y XXVII ordena que el Congreso tiene facultades:

XXVI. Para conceder licencia al Presidente de la República y para constituirse en Colegio Electoral y designar al ciudadano que deba substituir al Presidente de la República, ya sea con el carácter de interino o substituto, en los términos de los artículos 84 y 85 de esta Constitución;

XXVII. Para aceptar la renuncia del cargo de Presidente de la República.

Estos textos no fueron reformados en agosto de 2012 ni en febrero de 2014 y, sin embargo, debieron haber sido revisados no solamente por su lenguaje decimonónico y pasado de moda, sino también por no ser acordes al nuevo texto constitucional. En primer lugar, si se trata de licencia (que debe ser ante Congreso General), pues no hay necesidad de nombrar presidente interino o sustituto ya que para eso está el secretario de Gobernación. En segundo lugar, esos supuestos de la fracción XXVI, de nombrar presidente interino o sustituto, son más aplicables a los casos de una renuncia --la de la fracción XXVII-- y no de una licencia, pues para ello se reformó la Constitución, para que entre de manera expedita el secretario de Gobernación a suplir al presidente en funciones de manera provisional por faltas temporales de hasta sesenta días.

El numeral 5 de la Ley Orgánica del Congreso General de los Estados Unidos Mexicanos me da la razón de que para tratar los casos de los artículos 84, 85, 86 y 87 de la Constitución —además de lo relativo al informe presidencial previsto en el numeral 69 y otras sesiones 
solemnes - el que opera es el Congreso General y no el Congreso de la Unión, como puede deducirse de la siguiente redacción:

El Congreso se reunirá en sesión conjunta de las Cámaras para tratar los asuntos que previenen los artículos 69, 84, 85, 86 y 87 de la Constitución, así como para celebrar sesiones solemnes.

Asimismo, el artículo 8 de la misma ley orgánica resuelve el problema para determinar el quórum en sesiones de Congreso General, disponiendo que:

Para la realización de la sesión conjunta de las Cámaras, se requiere el quórum que para cada una de ellas se dispone en el primer párrafo del artículo 63 constitucional.

Es decir, se necesitan cuando menos 251 diputados de los quinientos posibles, y 65 senadores de los 128, para que las sesiones de Congreso General tengan validez, y no sumar simplemente 316 legisladores federales. Aquí sí el orden de los factores afecta al producto, porque de nada sirve que haya 500 diputados y solamente 64 senadores; o 128 senadores y 251 diputados. En la interpretación de estas disposiciones constitucionales el reconocido autor Pascual Alberto Orozco Garibay incurre en un error al sumar a los integrantes de ambas cámaras federales y afirmar que 419 es el número que da el quórum al Colegio Electoral. Es decir, el investigador de la Escuela Libre de Derecho no siguió para su interpretación lo ordenado en el numeral 63 de la Constitución y al 8 de la ley secundaria. ${ }^{19}$ Pero peor es la interpretación del jurista Enrique Sánchez Bringas cuando escribe que "Cuando la norma constitucional determina que ambas cámaras sesionen en una sola asamblea, el requisito del número mínimo de legisladores presentes es de más de la mitad de sus integrantes, o sea, 315 (sic) de los 628 legisladores..." 20

Además de estas insuficiencias, los miembros del poder reformador no llenaron un vacío constitucional que México tiene y que otros países menos desarrollados ya no: me refiero a que el Congreso o la Suprema Corte de Justicia le pidan dejar el cargo o que de plano se le revoque el mandato constitucional por diversas causales, es decir, desde violar de manera grave a la Constitución y a los derechos fundamentales como por locura o enfermedad mental o incapacidad física calificada por un grupo de profesionales de la psiquiatría. En la actualidad nuestra Constitución sólo prevé los casos en que el Ejecutivo Federal falta de manera temporal o definitiva, y que esa falta sea por un acto voluntario del presidente en funciones, ya sea licencia o renuncia o un acontecimiento grave como la muerte inesperada, pero no porque se lo pida un órgano soberano y legítimo que deje el cargo. En efecto, además de una muerte intempestiva, dolosa o accidental, y de una voluntaria renuncia o solicitud de licencia, no se contempla en nuestra Carta Magna el que se le solicite dejar el cargo por violaciones graves a la Constitución (juicio político), declaración de procedencia de responsabilidad penal (desafuero) o que se le revoque con todas las de la ley el mandato. Sabemos que un enfermo mental nunca va a reconocer su enfermedad y por lo mismo nunca va a pedir licencia o va a renunciar: al contrario, el enajenado mental va a exigir más poderes,

\footnotetext{
19 OROZCO GARIBAY, Pascual Alberto, Derecho Constitucional. El estado mexicano. Su estructura constitucional, $2^{a}$ ed., Porrúa-Centro de Investigación e Informática Jurídica-Escuela Libre de Derecho, México, 2011, p. 212.

${ }^{20}$ SÁNCHEZ BRINGAS, Carlos, Derecho Constitucional, $5^{\mathrm{a}}$ ed., Porrúa, México, 20oo, p. 414. 
inclusive los metaconstitucionales si es preciso. La solicitud de renuncia o licencia temporal es personalísima y si no la hace él nadie la puede hacer según la normatividad existente. En estos cuestionamientos me apoyo en Jorge Carpizo que fue de los primeros en cuestionar los vacíos constitucionales en la materia. ${ }^{21}$

Casos como el de Venezuela, recientemente, o el de Ecuador, hace unos veinte años, me dan la razón. Es necesario, pues, adicionar a la Carta de Querétaro con estas nuevas piezas de ingeniería constitucional.

En otro orden de ideas, y en relación a la Comisión Permanente que antes de la reforma podía nombrar presidente provisional y hasta interino, con la alteración al texto fundamental de agosto de 2012 se le quitó a este órgano dicha competencia dejándosele nada más la de recibir, en su caso, la protesta del presidente de la República, según la fracción II del artículo 78. El nuevo texto no dice más, pero se infiere que si hubo elección extraordinaria popular y directa de presidente de la República, o de que entró en funciones de encargado del Ejecutivo Federal el secretario de Gobernación y el Congreso no estuviere reunido, pues la Comisión Permanente le recibe la protesta, nada más, sin hacer designación ninguna, sólo es un acto receptivo y formal, no esencial o solemne. En el caso de que entre en funciones el presidente del Senado porque el presidente electo no se presenta de manera definitiva al empezar el período no daría lugar a que intervenga la Comisión Permanente, porque el $1^{\circ}$ de diciembre siempre hay sesiones ordinarias de Congreso de la Unión y resulta constitucionalmente imposible que esté funcionando la Comisión Permanente. Lo mismo se aplica para el año 2024 y subsecuentes períodos presidenciales en que el presidente de la República tomará posesión el 1 de octubre de cada seis años, según el numeral 83 y transitorios del texto reformado.

El artículo 87 constitucional dispone en su primer párrafo - no reformado en 2012- que:

El Presidente, al tomar posesión de su cargo, prestará ante el Congreso de la Unión o ante la Comisión Permanente, en los recesos de aquél, la siguiente protesta: «Protesto guardar y hacer guardar la Constitución Política de los Estados Unidos Mexicanos y las leyes que de ella emanen, y desempeñar leal y patrióticamente el cargo de Presidente de la República que el pueblo me ha conferido, mirando en todo por el bien y prosperidad de la Unión; y si así no lo hiciere que la Nación me lo demande.

En esta disposición no se distingue si es el presidente electo en elección popular directa ordinaria o extraordinaria, tampoco si es interino o sustituto o encargado provisional, por lo que afirmo que toda persona que ocupe el cargo de presidente de la República bajo cualquier denominación debe rendir la protesta. ${ }^{22}$ Refuerza mi idea el hecho de que no sólo el Congreso General la reciba, sino que también la Comisión Permanente cuando aquél no esté reunido: esto por aquello de que puede ser el presidente electo de manera extraordinaria en un plazo de entre siete y nueve meses a partir de que faltó de manera definitiva el presidente en funciones dentro de los dos primeros años del sexenio y pudiera darse el caso de que el presidente así electo debe rendir protesta en un plazo no mayor de siete días naturales a partir

\footnotetext{
${ }^{21}$ CARPIZO, Jorge, Op. Cit., pp. 66 y 68.

${ }^{22}$ Elisur Nava afirma que en el acto de la protesta los legisladores fungen como fedatarios del mismo. Además sostiene, que una variante u omisión en el momento de rendirse la protesta no anula el acto, en apoyo total a Vicente Fox y sus variantes guadalupanas y familiares del $1^{\circ}$ de diciembre del año 20oo. Véase ARTEAGA NAVA, Elisur, Op. Cit., pp. 300-301.
} 
de la elección extraordinaria y qué tal que el Congreso no esté reunido. En esta disposición también reafirmo, conforme a la ley secundaria, que se trata del Congreso General —no el Congreso de la Unión - el que recibe la protesta.

Siguiendo con el mismo numeral 87, en su afortunada reforma de 2012, se llenan vacíos constitucionales como el de ¿qué pasaría si el Congreso General no le recibiera la protesta al presidente electo? pues bien, el precepto reformado dispone en sus subsecuentes párrafos lo siguiente:

Si por cualquier circunstancia el Presidente no pudiere rendir la protesta en los términos del párrafo anterior, lo hará de inmediato ante las Mesas Directivas de las Cámaras del Congreso de la Unión.

En caso de que el Presidente no pudiere rendir la protesta ante el Congreso de la Unión, ante la Comisión Permanente o ante las Mesas Directivas de las Cámaras del Congreso de la Unión lo hará de inmediato ante el Presidente de la Suprema Corte de Justicia de la Nación.

Ya he dicho en líneas anteriores que aquí la reforma de agosto de 2012 sí fue muy afortunada al resolver una posible situación que ni la ley secundaria ni el reglamento congresional preveían. Con la reforma, el presidente electo va a poder rendir protesta ante Congreso General, Comisión Permanente, las mesas directivas de ambas cámaras, juntas, actuando al alimón, o ante el presidente de la Suprema Corte de Justicia de la Nación, no señalando la disposición constitucional dónde sería dicho acto formal - que no solemne- por lo que se facilitaría la rendición de tal protesta en un lugar adecuado y seguro, lejos de posibles actos de provocación como se estuvo en peligro en 2006 cuando el presidente electo tuvo que entrar por la parte trasera del palacio de San Lázaro en medio de gritos y empujones.

Parece que en materia de rendición de protesta todo está claro, sí, para el presidente electo de manera popular y directa en elecciones ordinarias o extraordinarias, pero no hay mucha claridad en cuanto al caso del secretario de Gobernación o el presidente del Senado que se encargarían provisionalmente del Poder Ejecutivo Federal. En cuanto al presidente del Senado que se encarga de asumir la presidencia de la República provisionalmente porque el presidente electo no se presenta de manera definitiva a rendir protesta, no me cabe la menor duda de que puede rendir protesta ante Congreso General, mesas directivas o ante el presidente de la Corte, porque los tiene a la mano, pero ¿qué pasaría con el secretario de Gobernación que asume el cargo por ministerio de ley? Ante lo oscuro de la enmienda en este tema, el diputado Jesús Rodríguez Hernández, vicepresidente de la Mesa Directiva en el tiempo de la reforma, sólo me contestó que ante la situación de emergencia en que llegaba el secretario de Gobernación a asumir la presidencia de la República "no era necesario el rendir protesta porque ya la había rendido como secretario de Gobernación”. Yo le contesto al licenciado Rodríguez que la obligación que impone el numeral 87 no distingue si eres electo de manera ordinaria o extraordinaria, sustituto, interino o encargado provisional, además de que al secretario de Gobernación le tomaron la protesta - concretamente su jefe el presidente de la República - , situación muy diferente a que la rinda como encargado provisional del Ejecutivo Federal. Una cosa es que te tomen la protesta y otra que la rindas. Que te la tomen es sinónimo de relación jerárquica. Además amables lectores, no en todos los casos en que el secretario de Gobernación asumiría el Poder Ejecutivo Federal por ministerio de ley sería de manera imprevista, porque puede darse el caso de que el presidente en funciones 
pida un permiso de hasta sesenta días para ausentarse y aquí habría la posibilidad y tiempo - crónica de una licencia anunciada - para que el encargado provisional rinda la protesta ante el órgano competente.

Para entender mejor mis dudas me permito presentar al amable lector varias hipótesis y sus probables respuestas:

1. El presidente de la República en funciones pide licencia para ausentarse de manera temporal hasta por sesenta días naturales. Aquí entra en sustitución el secretario de Gobernación como encargado provisional, y no creo que haya problema para que rinda la protesta ante el órgano competente al no haber una situación inesperada. Esto lo digo aunque el texto reformado sea omiso.

2. El presidente de la República en funciones se ausenta de manera definitiva — sin avisar al órgano legislativo - ya sea por enfermedad, accidente grave o muerte, en una situación completamente inesperada. En esta hipótesis de verdadera emergencia entraría el secretario de Gobernación a asumir el cargo con todos los poderes fácticos y constitucionales del Ejecutivo Federal, hasta por sesenta días en tanto no se reúna el Congreso General para designar presidente interino o sustituto, pero esto no exime al encargado provisional de rendir protesta ante órgano competente en cuanto se pueda. Cuando me refiero a "en cuanto se pueda", afirmo que en algún momento tiene que rendir la protesta ante las mesas directivas, Comisión Permanente o ante el presidente de la Corte, claro, sin dejar de asumir el cargo y todos sus poderes desde el momento mismo en que faltó el presidente en funciones. Por algo se llenó ese vacío que existía entre que se reunía el Congreso General o la Comisión Permanente para designar interino, sustituto o provisional según el texto constitucional anterior.

Para terminar el presente ensayo, sólo me referiré a otra situación que quedó en el debate de comisiones y de pleno en ambas cámaras federales, pero que se dejó omiso en el articulado de la Constitución: ¿el secretario de Gobernación encargado de manera provisional del Ejecutivo Federal o el presidente del Senado de la República que asume de manera provisional la titularidad del ejecutivo por falta definitiva del presidente electo pueden o no pueden ser ratificados como presidente interino o sustituto por el Congreso General sin haber dejado el cargo? Mucho se discutió en ambas cámaras, se llegó a la conclusión que no, que se violaría el artículo 83 de la Constitución, aunque hubo voces discordantes al considerar que sí era posible si es que en las hipótesis anteriormente citadas no habían dejado de ejercer el cargo ni por un momento. Total, que la conclusión fue de que no era posible que el secretario de Gobernación o el presidente del Senado encargados provisionales del Ejecutivo Federal fueran ratificados, pero eso lo sabemos solamente los que hemos leídos los dictámenes de comisiones y el diario de los debates, no dice nada el texto constitucional, ni el anterior ni el reformado.

Con estas reformas en el sistema de sustitución se convierte al secretario de Gobernación en un vicepresidente de la República virtual o en potencia, sujeto a faltas absolutas o temporales del presidente en funciones, pero también lo convierten en un producto desechable ya que una vez que ejerce aunque sea por un momento o hasta por sesenta días la presidencia de la República y deja el cargo ¿ya para qué lo quieres de nuevo como secretario de Gobernación si no podría ejercer nuevamente el cargo de presidente de la República ante un caso de emergencia? Si lo dejan nuevamente como secretario de Gobernación y se presenta nue- 
vamente la emergencia tendríamos que echar mano del reglamento interior de la Secretaría de Gobernación que prevé que si falta el titular de la dependencia lo sustituirán de manera provisional los subsecretarios del ramo en orden de prelación, llevando preferencia el subsecretario de Gobierno sobre los otros. Pero esto, repito, sería complicarse la vida política y México no está para experimentos constitucionales. Aunque el secretario de Gobernación encargado del Poder Ejecutivo Federal de manera provisional sea muy valioso mejor reacomódalo en otra dependencia o entidad donde no cause conflictos su presencia, porque de alguna manera pasaría a la historia nacional por haber ocupado aunque sea por sesenta días la máxima responsabilidad en el sistema político mexicano.

EPÍLOGO CON NUEVAS REFORMAS CONSTITUCIONALES AL EJECUTIVO FEDERAL PUBLICADAS EL 10 DE FEBRERO DE 2014

Dentro del paquete de reformas constitucionales, al que la jerga política llama "Reforma Político-Electoral", hubo varios cambios a las facultades del presidente de la República y a la fecha de toma de posesión que sin embargo entran en vacatio legis, porque su observancia se prorroga en unos aspectos al $1^{\circ}$ de diciembre de 2018 y en otros casos a 2024. De todas maneras consideré importante incluir esos aspectos en este trabajo.

El presidente de la República que entre en funciones en 2018 durará en su cargo cinco años diez meses, pues el numeral décimo quinto transitorio de la reforma en cita -la del 10 de febrero de 2014- ordena que el ciudadano electo presidente de la República en 2018 deberá entregar al siguiente candidato electo popularmente en elección ordinaria el 1 de octubre de 2024 .

Transcribo la disposición para mayor claridad:

Las reformas a los artículos 65; 74, fracción IV y 83 de esta Constitución entrarán en vigor el $1^{\circ}$ de diciembre de 2018, por lo que el período presidencial comprendido entre los años 2018 y 2024 iniciará el $1^{\circ}$ de diciembre de 2018 y concluirá el 30 de septiembre de $2024 .^{23}$

\footnotetext{
${ }^{23}$ Mi fuente es la versión de la Cámara de Diputados, Secretaría General y Secretaría de Servicios Parlamentarios de fecha 10 de febrero de 2014.
} 


\section{CONCLUSIONES}

1. Las reformas constitucionales de 2012 y 2014, en materia del Poder Ejecutivo Federal, fueron afortunadas en cuanto a la toma de posesión del presidente de la República y en que no quede nunca acéfalo dicho puesto ni por un breve lapso.

2. A pesar de las alteraciones referidas quedaron huecos legales e insuficiencias de lenguaje y técnica jurídicos que deben llenarse.

3. Es necesario señalarle al Ejecutivo Federal sujeción a juicio político por violaciones graves a la Constitución, y al Congreso General la competencia para remover al presidente de la República por notoria incapacidad física o mental.

4. De 1824 a 2014, hemos ensayado los mexicanos nueve maneras diferentes de sustituir al Ejecutivo Federal por faltas temporales y definitivas, siendo la mejor o menos defectuosa la que tenemos desde 1917 con las reformas de 2012 y 2014

5. El secretario de Gobernación o el presidente del Senado que ocupen provisionalmente la titularidad del Ejecutivo Federal no podrán ser ratificados como presidente interino o sustituto, aunque no hayan dejado el cargo.

6. Debe distinguirse claramente el Congreso General del Congreso de la Unión desde la Ley suprema y así evitar confusiones de terminología, competencia, quórum de asistencia y quórum de votación.

FUENTES

ARTEAGA NAVA, Elisur, Derecho Constitucional, $2^{\mathrm{a}}$ ed., Oxford University Press, México, 2001.

BRINGAS SÁNCHEZ, Enrique, Derecho Constitucional, $5^{\text {a }}$ ed., Porrúa, México, 2000.

BURGOA ORIHUELA, Ignacio, Derecho Constitucional Mexicano, $5^{a}$ ed., Porrúa, México, 1984.

CÁRDENAS CAMACHO, Alejandro, Diccionario jurídico mexicano, Instituto de Investigaciones Jurídicas-UNAM-Porrúa, México, 2005.

CARPIZO, Jorge, El presidencialismo mexicano, $5^{\text {a }}$ ed., Siglo veintiuno editores, México, 1985.

Estudios Constitucionales, $2^{\mathrm{a}}$ ed., Instituto de Investigaciones jurídicasUNAM, México, 1983.

SÁNCHEZ BRINGAS, Carlos, Derecho Constitucional, $5^{a}$ ed., Porrúa, México, 2000.

SOBERÓN MAINERO, Miguel, Diccionario jurídico mexicano, Instituto de Investigaciones Jurídicas-UNAM-Porrúa, México, 2005. 
MORENO, Daniel, Derecho Constitucional Mexicano, 6a ed., Editorial Pax México, México, 1981.

OROZCO GARIBAY, Pascual Alberto, Derecho Constitucional. El estado mexicano. Su estructura constitucional, $2^{\mathrm{a}}$ ed., Porrúa-Centro de Investigación e Informática Jurídica-Escuela Libre de Derecho, México, 2011.

SAYEG HELÚ, Jorge, Instituciones de Derecho Constitucional Mexicano, Porrúa, México, 1987.

TENA RAMíREZ, Felipe, Derecho Constitucional Mexicano, 29ª ed., Porrúa, México, 1995.

LEGISLACIÓN

Constitución Política de los Estados Unidos Mexicanos, texto vigente, 2014.

Ley Orgánica del Congreso General de los Estados Unidos Mexicanos.

Dictamen de abril 22 de 2012 en la Cámara de Diputados. Secretaría General y Secretaría de Servicios Parlamentarios de fecha 10 de febrero de 2014. 